\title{
Influences of Internet on University Students' Communication and Realistic Reflections*
}

\author{
Bo Yang \\ Doctoral candidate of the ideological and political education \\ in Humanities and Social Science \\ Dalian University of Technology \\ Dalian, Liaoning, China
}

\author{
Yanjun Dai \\ Professor, doctoral tutor of Humanities and Social \\ Science \\ Dalian University of Technology \\ Dalian, Liaoning, China
}

\begin{abstract}
With the fast development of modern technology, Internet has become one of the most important factors that influence university students' study and life: breaking realistic barriers to students' discourse communications, opening up a new field in learning communication, cyber love opening a new model of emotional communication, unignred the influences of internet addiction on interpersonal communication among university students and so on. The Internet is said to be a double-edged sword for students and its rapid development seems an irresistible tide. Students can learn many useful things to enrich and improve themselves in the wave, but they could also be rolled down by the fierce spindrift. How to take advantage of information transmission of Internet is an important problem that both university students and modern society should take into account.
\end{abstract}

Keywords_—Internet; university students; communication; influences; realistic reflections

\section{INTRODUCTION}

The Internet began in 1969 and is a revolution in human communication technology. Since then great changes have taken place in human communication. University students, as a main force in society, also start to show interest in the Internet and are deeply affected by it.

\section{INTERNET BREAKING REALISTIC BARRIERS TO STUDENTS' DISCOURSE COMMUNICATIONS}

Tencent was founded in 1998 and has presented a solution to wireless Internet paging, opening a door to Internet communication in China. University students, as a newly-born force in society, are the most sensitive group to the Internet. As soon as QQ is launched, it has been favored and welcomed by numerous university students. When QQ starts its first operation, it is mainly for online chatting. Where there is the Internet, there is QQ. But for university students' economy level, QQ is the most suitable chatting tool because of no additional charge and they prefer QQ. Whether a single digit QQ number at the very start or more than ten digits nowadays, it sees the impact of QQ on university students. Then the popularity of MNS in China makes communication even more internationalized. MNS,

*This paper is for "Specific subjects(public management)teaching reform in Liaoning province research projects"— "Study of contemporary university students' professional view and its education path", item no.GGGLKY-26 the full name for MNS Massager, which is a communication tool launched by Microsoft, has the same function with QQ. However, with much more internationality added, MNS makes scopes of communication more broad. It is also wellreceived by university students due to the fact that its connection has spread to the international stage. If university students were provided with a platform for exchange and communication by QQ, MNS etc., then Forum, BBS and Post Bar are places where university students' bright thoughts crisscross. In the last few years, college BBS has become a backbone of BBSs. Shuimu Community, Guanhaitingtao and other college BBSs are very famous among the college forums. The forum can be used for more than just speech freedom for university students. There is much information both on your own college and on every aspect of students' study and life. At the same time, students can communicate with each other in water districts and BBS turns out to be a rare source of information for university students. Baidu Post Bar was created on December 3, 2003 and the reason why it is created is that building an online exchange platform combining the search engine is convenient for people, who have an interest in the same topic, to get together to communicate and help each other. Baidu Post Bar, once established, its popularity has soared. It involves a broad area that you cannot imagine. There is no Post Bar that cannot be searched out as long as you can imagine, which is in exact line with university students' various needs. Whether it is the information on stars or the items and events which you are intrigued with, Post Bar could always meet the needs of university students. In December, 2015, Xiaonei was established and has quickly become a monopoly on the campus websites in Chinese university student markets. And a heavy storm of Xiaonei has risen. The information and profiles posted by individuals is authentic, which is not possible on QQ, MNS and other virtual worlds. Xiaonei, as a new way for social contact, truly connects people around, and people can receive clear messages at any time and feel their life and its changes. From virtualization to reality, Xiaonei has helped Internet communication get more rationalized. University students no longer disguise what is really in their hearts and they put the authentic themselves on the Internet. The Blog began to enter China in 2000 and developed promptly. It is a website or an online diary, which is managed by yourself. You can post 
new articles, pictures or videos to express feelings or share information. In March, 2006, a new company named Obvious, set up by Evan Williams who is a pioneer in blogging, created Micro-blog. Once created, it is favored by broad mobile phone netizens. Especially post-90s university students, they came upon the popularity of Micro-blog once they entered school and became the first mainstream for Micro-blog use. Tencent launched a free application, Wechat, on February 21, 2011, which offers an instant communication for smart terminals. It supports a program, which crosses communication carriers and operating systems to send free voice messages, videos, pictures and words. And you can also employ shared information through streaming media and enjoy services of social plug-ins, based on your position, such as Shake, Drift Bottle, Moments, Official Platform and Audio Recording MEMO. It is recognized as the most well-known Internet communication platform at present.

The Internet has changed university students' way of discourse communication, whether it is QQ, MNS, Forum, Post Bar, Xiaonei, or today's Micro-blog, Wechat, the Internet communication has deeply affected university students' lifestyles. Not only does it make university students present themselves, show their personalities and awaken their communications, but also it allows this kind of communication to increasingly become mature and rational. University students begin to transform from casual information exchange to the notice and concerns for events around initiatively. They also make communication channels become more spacious. We can say that the Internet allows university students' way of communication to complete a leap from a closed situation to a liberated one.

\section{INTERNET OPENING UP A NEW FIELD IN LEARNING COMMUNICATION}

The network environment, knowledge is like a kaleidoscope, which is various and full of wonders. Former school teaching is lecture-based. Teachers impart knowledge to students by blackboard writing and students take notes while listening. This kind of teaching is very difficult to do "tailoring teaching". Conditions are that dozens of students in one class use the same textbook, receive the same teacher's same education, do the same homework and take the same examination, therefore, there always appears a phenomenon that "some people don't get enough to eat and some cannot swallow". But the Internet's appearance raised a storm and has upended the past inflexible and entrenched teaching. Teachers can have their own online classes and put their course wares and videos on the Internet through the Internet. Meanwhile, students can also study easily at home without worrying not knowing any classical word of teachers. And the popularity of the Internet makes learning resources be shared among many people at the same time and solves the problem of unequal distribution of learning resources. Second, the mass storage of the Internet can provide students with sufficient Internet resources. They can take suitable resources to study according to their own situations, which proves to be a good embodiment of "tailoring teaching" and ensures each student improves to varying degrees and the education is pertinent.

Under the interactive teaching of multimedia, students can use their listening, speaking, reading and writing, which can arouse the enthusiasm well and enhance the interest of learning. In addition, it makes students alter from passive learning that "teachers are teaching and students are learning" to the style that students initially want to study. At the same time, from the Internet students can both acquire knowledge and heighten their abilities of handing, practicing and searching, summarizing and generalizing information from all the Internet resources, which cannot be learned in the past classrooms and is also precisely what the new generation should equip.

The influence of Internet on teaching and learning is certainly more than these. With the maturity of Internet technology and the enrichment of Internet resources, online teaching and learning will become something of a fad. Its impact on classroom teaching will continue to reinforce, and if we can get familiar with the Internet in a right way and can make the best of the Internet, it can yet be regarded as another key to the implementation of quality education. It is believed that the Internet is bringing a new revolution for learning and is growing to be a new milestone.

\section{Cyber Love Opening a New Model of EMOTIONAL COMMUNICATION AMONG UNIVERSITY STUDENTS}

Love on the Internet, namely "cyber love", is taking place quietly among university students. As a comment on the education network has written, if the buzzword of university students in 1999 was "Do you go abroad" and the buzzword in 2000 was "Do you take part in the postgraduate entrance exams", then the buzzword in universities has changed into "Do you have cyber love" nowadays. You can see how amazing cyber love penetrates among university students!

In the virtual world, not only cannot we judge others' appearances, but also we may not even know their genders or ages. We often hear people around say that the handsome boys or beauties who used to chat hotly on the Internet turn out to have the same gender with them or prove to be old uncles or aunts. The "Internet addiction" triggered by the curiosity at cyber love among most university students has greatly influenced their normal study. They often go to Internet bars, computer rooms or stay at bedroom spending a long time on the Internet like fighting in an everlasting war, waiting for the QQ named "cute you" to go on line. In contrast, they either feel sleepy or are depressed and glazed in class. Worst of all, there have appeared some outlaws sequentially, who do evil through the Internet especially using the way of Internet chatting. They either spend a long time in cultivating stable relationships and preparing for kiting or use guerilla tactics to lure girls. Examples of university students cheated are everywhere.

For these appeared problems above, the reason is mainly the virtuality of Internet. Many people yearn for the romance 
of cyber love because it is full of their own reverie and expectation. But the reverie and expectation tending to be perfect, is unilateral and not in accordance with the objective facts, and makes a lot of university students lose their minds and judgments. They see only the person who they imagine instead of the reality. When ideality is replaced by reality and everything comes out in the wash, the outcome is always so unexpected and even depressed and desperate.

Not only does the development of Internet bring us quicker and more convenient services, but also it brings us many disadvantages that are hard to prevent. It is imperative to strengthen young students' self-protection and selfdiscipline. The reinforcement of Internet monitoring and rectification through all circles of the society is absolutely necessary.

\section{UNIGNORED THE INFLUENCES OF INTERNET ADDICTION ON INTERPERSONAL COMMUNICATION AMOMG UNIVERSITY STUDENTS}

For university students, one of the most massive charms brought by the Internet is from online games. With the development of Internet, we have witnessed the birth of Internet bars in cities around the country and the computer games from stand-alone to network era. More and more exquisite games enrich generations of university students' life and they also cause numerous social problems. Tragedies caused by the game addition are most shocking.

In 1999, computers in China are far from the universal now, but the budding Internet bar industry has attracted much attention from many teenagers by popular computer games, such as "Half Life", "Red Alert" and other smash-hit games. "Charm Treasure" and "Stone Age", the representatives of the small-scale online games, began around 2000 and "Legend" was brought to China at the end of 2001. Many Chinese players start to know online games through "Legend". "'Boast Swims on the West Two", as a national online game, achieved great success in 2003 and "Legend" opened a free era for Chinese online games free of charge in 2005. And then there existed Warcraft, Three Killed, Dota, CF (Cross Fire), Plants vs. Zombies and other games and they all have changed from stand-alone to online games and from computer terminals to mobile terminals. Modern university students, on behalf of Chinese youth, have witnessed the birth of many classical games and they also have grown up with the continuous innovation and progress of online games. Until now, small and large Internet bars can be seen around schools here and there and the campus Internet of each university has also covered every bedroom. And university students always vent in the virtual world owing to the pressure from study and difficulties in their lives. It is easier to achieve young people's dreams to be heroes in online games and all you need to pay is time and money. Therefore, the combination of more convenient access to the Internet, the need for relaxation in life and the perusing of dreams allow online games to have a tremendous attraction to modern university students.

But irritative battles appeared in online games all the time and the need of much money for characters and equipment to be upgraded cause many social problems, too. Examples are that students are addicted to the Internet and become irresistible and this kind of situation happened around us occasionally. Only in 2006, there were 90 students in Zhejiang University who dropped out of school, of whom more than 60 students are Internet addicts, accounting for $80 \%$ of the drop outs. In the same year, unexpectedly there were 336 students who were persuaded to drop out of school because of their poor grades and insufficient credits in Xi' an University of Posts \& Telecommunications. Meanwhile, 113 university students were also persuaded to drop out in Xuzhou, Jiangsu, of whom many are addicted to the Internet. An investigation made by the Institute of Psychology, Chinese Academy of Sciences on thirteen universities all over the country has showed that the problem of Internet addiction for university students is more and more severe and $80 \%$ students stop their education, including dropping out and stopping of school, caused all by Internet addiction. Many excellent students get irresistible to temptations of games and Internet, which destroys their futures and hurts the whole family at the same time.

Although problems reflected by the previous data are worth considering, most of the university students are not addicted to online games. Even so, online games waste their precious time and impact their study and life. The online game, as a way of entertainment, is positive because it can help them relieve stress from study and life and seek for sense of belonging and respect which is absent in life and it can also make them socialized in advance. But how to guide university students to use the Internet correctly and spend time properly has become an important subject that students, universities, families and the society should research on.

From a stage to show personality to a bridge for exchange and communication, from a channel to disseminate information to a classroom for knowledge learning, from the convenience and speediness of online shopping to the virtual "love" from the virtual world, the Internet has brought a number of revolutionary changes and university students' life has completely changed during this time. As a product of social progress, the popularization and development of the Internet are epitomes of human's wisdom and also an irreversible trend under the globalization. Although many social problems emerge and university students' growth is greatly influenced, the real source of these problems does not lie in the Internet itself. It rests on many education defects and system loopholes, which needs wisdom and strength from the whole society to solve.

\section{REFERENCES}

[1] Network Communication Platform. http://baike.baidu.com.

[2] Statistical report on behaviors of China mobile Internet users in 2015.

[3] The thirtty-seventh statistical report on Internet development in China in 2016.

[4] Wei Wang and Mingze, Sun, "A brief analysis of reasons for university students' addiction to the Internet" Theory Research. Harbin. Vol. 6, pp. 173-174, January 2001. 